\title{
3D geospatial modelling and visualization for marine environment: Study of the marine pelagic ecosystem of the south-eastern Beaufort Sea, Canadian Arctic
}

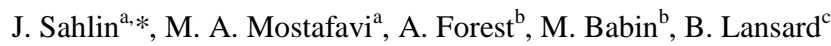 \\ ${ }^{a}$ Dept. of Geomatic Sciences, Université Laval, Québec, Canada - Per-Jonas.Sahlin.1@ulaval.ca, Mir- \\ Abolfazl.Mostafavi@scg.ulaval.ca \\ ${ }^{\mathrm{b}}$ Takuvik Joint International Laboratory, Université Laval (Canada) - CNRS (France), Département de Biologie and Québec-Océan, \\ Université Laval, G1V 0A6, Canada - (Alexandre.Forest, Marcel.Babin)@takuvik.ulaval.ca. \\ ${ }^{\mathrm{c}}$ LEGOS, Laboratoire d'Études en Géophysique et Océanographie spatiales, CNRS-UPS-CNES, 31400 Toulouse, France - \\ bruno.lansard@legos.obs-mip.fr
}

KEY WORDS: GIS, Oceanography, Visualization, Spatial, Modelling, Three-dimensional, Interpretation

\begin{abstract}
:
Geospatial modelling of the marine pelagic ecosystem is challenging due to its dynamic and volumetric nature. Consequently, conventional oceanographic spatial analysis of this environment is in a $2 \mathrm{D}$ environment, limited to static cutting planes in horizontal and vertical sections to present various phenomena. In this paper, we explore the contribution of recent 3D development in GIS and in scientific visualization tools for representation and analyses of oceanographic data sets. The advantages of a 3D solution are illustrated with a 3D geospatial voxel representation of water masses distribution in the southeastern Beaufort Sea (west of the Canadian Arctic).
\end{abstract}

\section{INTRODUCTION}

Oceans cover $71 \%$ of the Earth's surface and with an average depth of approximately $4000 \mathrm{~m}$, the volume of the marine pelagic ecosystem (water column) represent $99 \%$ of the biosphere (Angel, 1993). From a geospatial modelling perspective, this environment imposes different challenges compared to the terrestrial system. Whereas the latter is most often represented as an empty space filled with object (trees, houses etc...), the pelagic ecosystem is a continuous abiotic and biotic spatial geographical phenomenon in a full threedimensional (3D) environment. Study of the marine ecosystem, as well as management and conservation of marine resources, can be enhanced with adequate geospatial 3D modelling.

Traditional Geographic Information Systems (GIS), that are leading tools for the study and observation of spatial data, are not suitable to model geoscientific datasets since they have been principally designed for static and two-dimensional (2D) objects in terrestrial applications (Carette et al., 2008; Ledoux and Gold, 2008; Wright and Goodchild, 1997). Nevertheless, recent 3D GIS development justifies an update of their potential for marine pelagic geospatial modelling. Although lacking much of the flexibility in data management and ease of use of GIS, various specific scientific visualization tools have also been developed for modelling of the geologic subsoil, mainly motivated by oil and gas industry. These geomodelling tools are interesting from an oceanographer's perspective in that they treat, at least partially, the same type of continuous field as we find in the pelagic ecosystem.

In this paper, we first analyse and compare the capacity of different GIS tools for representation, visualization and analysis of a 3D dynamic marine environment. Specifically, we conduct a qualitative comparison between capacities of commercial GIS, commercial marine GIS, and academic prototype GIS as well as geomodelling tools (section 2). We demonstrate how recent development in 3D spatial modelling tools can improve representation, visualization and analyses of oceanographic phenomena and highlight some improvements that should be carried out to these tools in order to achieve an optimal marine spatial modelling tool. Finally, we propose an integration of the benefits from 3D geomodelling tools with advantages of GIS to improve 3D spatial modelling of oceanographic data sets. The third part of the paper is devoted to a case study proposing a 3D solution to visualization of water masses distribution in the southeastern Beaufort Sea (west of the Canadian Arctic). The data for this case study were obtained from the Malina oceanographic campaign conducted over the Mackenzie shelf between the $31^{\text {th }}$ of July and $26^{\text {th }}$ of August in 2009 (Figure 1). More detailed information about the Malina campaign can be found elsewhere (e.g. Matsuoka et al. 2012).

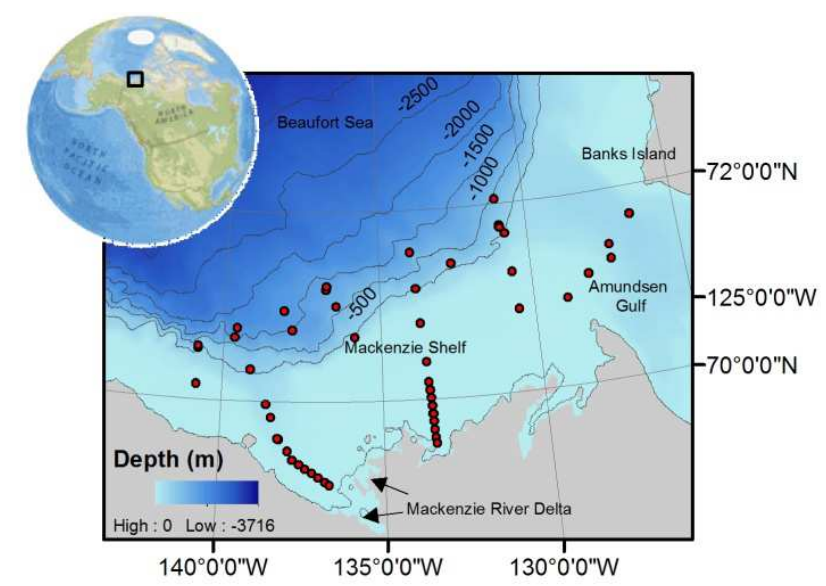

Figure 1. Location of sampling stations for the Malina cruise in the Beaufort Sea, Canadian Arctic.

\footnotetext{
Corresponding author.
} 


\section{3D SPATIAL REPRESENTATION OF THE PELAGIC ECOSYSTEM}

Pelagic marine features are characterized by their fuzzy boundaries, dynamic, and full 3D structure (Gold and Condal, 1995; Shyue and Tsai, 1996). These characteristics are restrictive for data acquisition, as well as for geospatial modelling and representation. A further problem with oceanographic data sets is the frequent anisotropic distribution of data, due primarily to logistics and costs associated with expensive sampling at sea. Development of tools available for 3D geospatial modelling of the marine pelagic ecosystem is consequently challenging. This might explain why conventional analysis of oceanographic phenomena is traditionally in a $2 \mathrm{D}$ environment, limited to static cutting planes in horizontal and vertical sections either contoured or colour-coded to present various parameters (Head et al., 1997).

Oceanic physical parameters, such as temperature and salinity, define distinct water masses with more or less fuzzy boundaries. Vertical and horizontal distribution of these water masses influences the oceanic carbon cycles, which in turn play an important role in regulating global climate. One partial objective of the Malina oceanographic campaign was to gain better understanding of these interactions. Visualization and spatial analyses in a 3D geospatial model of these phenomena can then be of great value. Such a model could also be of good use in a resource management or conservation perspective.

A summary of some common and specialised tools reviewed in this work are listed in Table 1 . These have been evaluated according to criteria for their suitability for 3D geospatial modelling of the pelagic environment. This review indicates that recent efforts of 3D development in the GIS field have mostly focused on object centred conceptual design using vector structures (for example: ArcGIS version 10, Fledermaus). Indeed, several research teams have recognized the lack of adequate 3D marine GIS (Arsenault et al., 2004; Mesick et al., 2009). We consider that an adequate representation of marine pelagic continuous phenomena needs fully developed volumetric field representations. That kind of representation is more developed in geomodelling tools. The general solution is the use of $3 \mathrm{D}$ raster-based models, commonly referred to as voxel (VOlume piXEL) structures. Although in use since the beginning of 1990, they are still mostly absent in commercial GIS (the GIS open-source GRASS might however be an exception to this generality, offering limited volume rendering). It is also worth noticing that the more dynamic data structures Voronoï tessellations, whose advantages have been stressed in various academic works (Beni et al., 2011; Ledoux and Gold, 2008), are absent so far in commercial geospatial modelling tools. A draw-back with the geomodelling tool reviewed in this paper is its limited ability for image treatment and analyses, imperative in oceanographic research considering the common use of remote sensing. Another essential function for an optimal marine geospatial modelling tool is the visualization of $2 \mathrm{D}$ static cuts in vertical direction. Even though such a function might seem trivial and does not require a true 3D interpolation method, this operation is not possible at present with ArcGIS and very limited with EnterVol, commercial extension to ArcGIS that permits volumetric representation (Table 1). Finally, none of the tools evaluated permit to take into consideration the dynamic nature and fuzzy boundaries of pelagic phenomena or to assess a general predictive capability of spatial 3D models, such as cross-validation (e.g. Foglia et al. 2007).

\begin{tabular}{|c|c|c|c|c|c|}
\hline Criteria & ArcGIS 10 & Fledermaus & HabitatSpace & CTech EnterVol & Paradigm Gocad \\
\hline & $\begin{array}{c}\text { Commercial } \\
\text { GIS }\end{array}$ & $\begin{array}{c}\text { Commercial } \\
\text { marine GIS }\end{array}$ & $\begin{array}{c}\text { Academic } \\
\text { prototype GIS }\end{array}$ & Extension to ArcGIS & Geomodelling tools \\
\hline 3D Interpolation & - & Limited & (Kriging) & Kriging (limited), IDW & Kriging, IDW, other. \\
\hline 3D raster representation & - & Limited & $\checkmark$ & $\checkmark$ & $\checkmark$ \\
\hline 3D vector representation & $\checkmark$ & $\checkmark$ & $\checkmark$ & & $\checkmark$ \\
\hline Visualization cuts & - & $\checkmark$ & $?$ & $\checkmark$ & $\checkmark$ \\
\hline Visualization iso-surfaces & - & $\checkmark$ & $\checkmark$ & $\checkmark$ & $\checkmark$ \\
\hline Visualization volumes & - & - & Limited & $\checkmark$ & $\checkmark$ \\
\hline 3D statistical analyses & - & - & $?$ & $\checkmark$ & $\checkmark$ \\
\hline 3D spatial analyses & - & - & Limited & $\checkmark$ & $\checkmark$ \\
\hline
\end{tabular}

Table 1. Review of five geospatial modelling tools from commercial and academic GIS as well as from geomodelling.

\section{3D GEOSPATIAL SOLUTION TO REPRESENTATION OF WATER MASSES DISTRIBUTION: MALINA CASE STUDY}

In the south-eastern Beaufort Sea, several types of water masses can be identified, such as the nutrient rich pacific Upper Halocline Water (UHW). The fractional presence of UHW was obtained for each of the 243 sampling points (x, y, z) accordingly to a method described by Lansard et al. (2012). A geospatial voxel model of this water mass was constructed with Paradigm GOCAD, a scientific visualization tool developed for 3D geological spatial modelling. This spatial model was built by a grid of $150 \times 75 \times 100$ voxels in $\mathrm{x}, \mathrm{y}, \mathrm{z}$ direction and compressed vertically between water surface and bathymetric surface. UHW values were attributed to each voxel in the model through a $3 \mathrm{D}$ interpolation of sampling points with ordinary kriging.

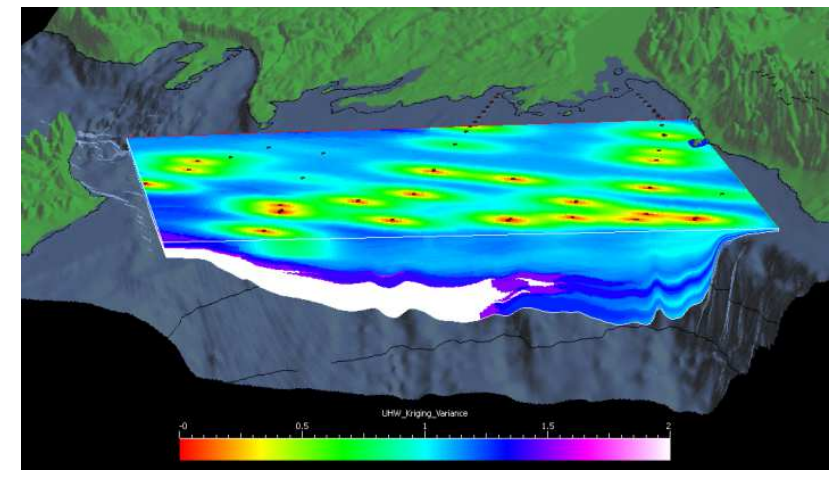

Figure 2. Kriging variance of spatial 3D model for pacific Upper Halocline Water in the Beaufort Sea. Black dots indicate sampling points. 
The kriging variogram's dependent predictive error is presented in Figure 2. In general, the lower the error for a specific location, the better is the prediction of the spatial model.

The final spatial model permits us to visualize iso-surfaces and volumes as well as cuts in any plane of the water mass (Figure
3) and enables spatial 3D analyses, such as volume calculation and intersection. This case study shows that recent advances in volumetric representation developed primarily for geomodelling tools can be used to extend usual interpretation of static marine pelagic phenomena from $2 \mathrm{D}$ static planes to a true $3 \mathrm{D}$ environment.

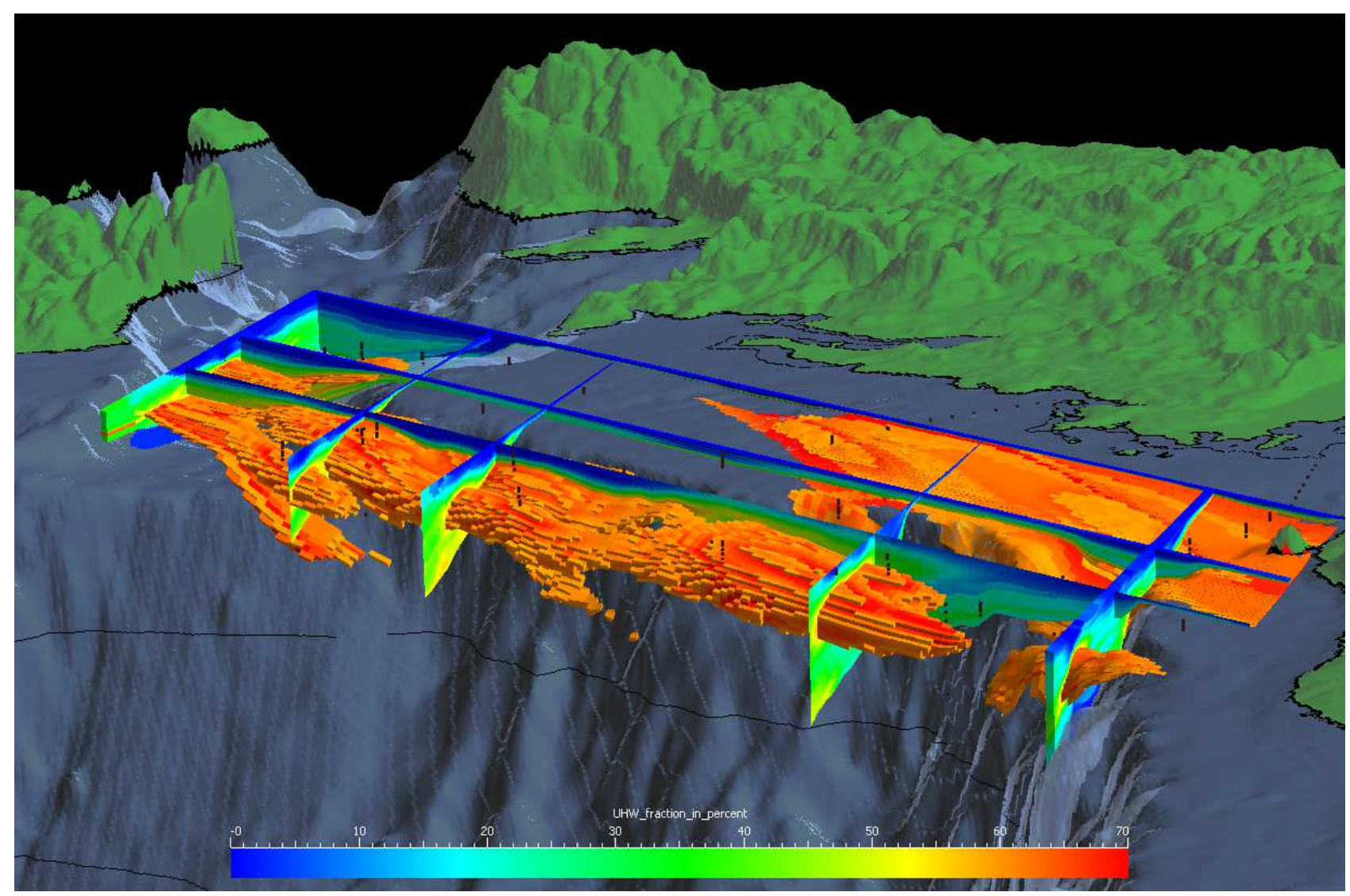

Figure 3. Geospatial representation of Upper Halocline Water on the Mackenzie shelf in summer 2009. This snapshot illustrates approximately the upper $500 \mathrm{~m}$ of the water mass contained within the spatial model. Scale indicates fraction (\%) of water constituted of UHW and voxels containing more than $60 \%$ of UHW are coloured-filled. Visible sampling points are indicated by black dots. Vertical exaggeration in figure is 75 times that of reality. Spatial model was constructed with Paradigm Gocad.

\section{DISCUSSION AND CONCLUSIONS}

This research has explored the potential of 3D geospatial modelling tools for the study of marine pelagic ecosystems. A review of common GIS indicates that these software products mostly lack the necessary functions for volumetric representation of gradual phenomena, primordial for geospatial study of marine ecosystems. However, performance of geomodelling tools for representation of this environment is promising, which is illustrated in this paper by a snap-shot of a $3 \mathrm{D}$ solution to visualization of a water mass in the south-eastern Beaufort Sea, constructed with Paradigm Gocad (Figure 3). Integration of volumetric representation in a GIS environment is an important advance towards an optimal marine GIS. This tool must also include representation and analyses functions of $2 \mathrm{D}$ static vertical cuts. On the contrary, geomodelling tools could be adapted to the marine environment by improving basic functions for oceanographic research such as image treatment and analyses. However, all spatial modelling tools conceived for the pelagic environment would also benefit from including spatial data structure that takes into consideration the dynamic nature and fuzzy boundaries of the pelagic environment.
Our future research will explore the contribution of 3D geospatial modelling tools for the combination of satellite and ground data in the identification of biological hot-spots and organic carbon fluxes in the Beaufort Sea.

\section{ACKNOWLEDGEMENTS}

The authors are grateful for the partial financial contribution to this project from Natural Sciences and Engineering Research Council of Canada.

\section{REFERENCES}

Angel, M. V, 1993. Biodiversity of the pelagic ocean. Conservation Biology, 7(4), pp. 760-772.

Arsenault, R., C. Ware, M. Plumlee, S. Martin, L. L. Whitcomb, D. Wiley, T. Gross and A. Bilgili, 2004. A system for visualizing time varying oceanographic 3D data. In: Oceans ' 04 
Mts/Ieee Techno-Ocean '04, Vols 1- 2, Conference Proceedings, Kobe, Japan, pp. 743-747.

Beni, L. H., M. A. Mostafavi, J. Pouliot and M. Gavrilova, 2011. Toward 3D spatial dynamic field simulation within GIS using kinetic Voronoi diagram and Delaunay tetrahedralization. International Journal of Geographical Information Science, 25(1), pp. 25-50.

Carette, V., M. A. Mostafavi and R. Devillers, 2008. Towards Marine Geographic Information Systems: Multidimensional Representation of Fish aggregations and Their Spatiotemporal Evolutions. In: Oceans 2008, Vols 1-4, pp. 531-540.

Foglia, L., S. W. Mehl, M. C. Hill, P. Perona and P. Burlando, 2007. Testing alternative ground water models using crossvalidation and other methods. Ground Water 45(5), pp. 627641.

Gold, C. and A. R. Condal, 1995. A spatial data structure Integrating GIS and Simulation in a Marine Environment. Marine Geodesy, 18, pp. 213-228.

Head, M. E. M., P. Luong, J. H. Costolo, K. Countryman and C. Szczechowski, 1997. Applications of 3-D visualizations of oceanographic data bases. Paper presented at Oceans '97 Mts/Ieee Conference Proceedings, Vols. 1-2, pp. 1210-1215.

Lansard, B., A. Mucci, L. A. Miller, R. W. Macdonald, and Y. Gratton, 2012. Seasonal variability of water mass distribution in the southeastern Beaufort Sea determined by total alkalinity and $\delta^{18} \mathrm{O}$, Journal of Geophysical Research, Vol 117, $19 \mathrm{p}$.
Ledoux, H. and C. M. Gold, 2008. Modelling three-dimensional geoscientific fields with the Voronoi diagram and its dual. International Journal of Geographical Information Science, 22(5), pp. 547-574.

Matsuoka, A., Bricaud, A., Benner, R., Para, J., Sempéré, R., Prieur, L., Bélanger, S. and M. Babin, 2012. Tracing the transport of colored dissolved organic matter in water masses of the Southern Beaufort Sea: relationship with hydrographic characteristics, Biogeosciences, 9, pp. 925-940.

Mesick, S. M., T. C. Vance, C. J. Beegle-Krauss and D. Steube, 2009. HabitatSpace: Multidimensional Characterization of Pelagic Essential Fish Habitat. In: Oceans 2009, Vols 1-3, pp. 1953-1961.

Shyue, S. W., and P. Y. Tsai, 1996. A study on the dimensional aspect of the marine geographic information systems. Paper presented at Oceans '96 Mts/leee, Vols 1-3 / Supplementary Proceedings: Coastal Ocean - Prospects for the 21st Century, pp. 674-679.

Wright, D. J., and M. F. Goodchild, 1997. Data from the deep: Implications for the GIS community. International Journal of Geographical Information Science, 11(6), pp. 523-528. 